\title{
To Assess the High Blood Fat Nutritional Profile, Dietary Intake and the Effect of Hyperlipidaemia on the Health of Males and Females (Middle age group) of Prayagraj District Uttar Pradesh
}

\author{
Kushwaha Pratibha*, Gupta Alka and Paul Virginia \\ Department of Food Nutrition and Public Health, SHUATS, Prayagraj, India \\ *Corresponding author
}

\begin{abstract}
A B S T R A C T
Keywords

Hypercholesterolemia,

Hypertriglycerid-

emia,

Hyperlipidemia,

Exercise, Healthy

foods

Article Info

Accepted:

xx December 2020

Available Online:

xx January 2021

Hyperlipidemia Lipid is the scientific term for fats in the blood. At proper levels, lipids perform vital operations in our body, but it can also cause health problems if they are present in more amounts. The term means high lipid levels. Hyperlipidemia includes several conditions, but it usually means that you have high cholesterol and high triglyceride levels. Cholesterol is a waxy substance made by the body and also comes from the diet. High cholesterol in body is also commonly known as hyperlipidemia. It is a common problem which may deposit extra fats in the blood. Hyperlipidemia is the leading risk factor for cardiovascular diseases. Cholesterol and triglycerides together make it difficult for blood to pass by narrowing the blood vessels. This review basically focuses on the causes, types, diagnosis, symptoms and treatment of hyperlipidemia. It may be treated by changing life style, eating healthy food, doing exercise but several medications are also available in the market.

\section{Introduction}

Hyperlipidemia is an increase in one or more of the plasma lipids, including triglycerides, cholesterol, cholesterol esters and phospholipids and or plasma lipoproteins including very low-density lipoprotein and low-density lipoprotein, and reduced highdensity lipoprotein levels (Mishra, 2011). Hyperlipidemia is considered one of the major risk factors causing cardiovascular diseases (CVDs).CVDs accounts for one third of total deaths around the world, it is believed

that CVDs will turn out to be the main cause of death and disability worldwide by the year 2020. Ginghina, (2011). Cholesterol is a waxy substance made by the body and also comes from the diet. High cholesterol in body is also commonly known as hyperlipidemia. It is a common problem which may deposit extra fats in the blood. Hyperlipidemia is the leading risk factor for cardiovascular diseases. Cholesterol and triglycerides together make it difficult for blood to pass by narrowing the blood vessels. This review basically focuses on the causes, types, diagnosis, symptoms and
\end{abstract}


treatment of hyperlipidemia. It may be treated by changing life style, eating healthy food, doing exercise but several medications are also available in the market. Hyperlipidemia is caused when your diet contains too much cholesterol and fat (e.g., meat, cheese, cream, eggs, shellfish, etc.), when the body produces too much cholesterol and fat, or both. Hyperlipidaemia normally refers to high concentrations of the blood lipids, cholesterol, and triglycerides. These high levels reflect underlying changes in lipoproteins, and could be caused by overproduction, reduced catabolism or both. Thus, high levels of triglycerides reflect elevated concentrations of the triglyceride-rich lipoproteins, chylomicrons and VLDL, and their remnants. An increase in cholesterol concentration usually reflects an increase in LDL, with or without an accompanying increase in VLDL. Occasionally, raised total cholesterol may be due to a very high HDL alone. Hyperlipidemia may be secondary to other medical disorders or therapy, or it may be primary. Primary hyperlipidemia may be caused by a single gene defect or, more commonly, by a polygenic background influenced by environmental factors. Originally, primary (inherited) disorders were classified on the physicochemical characteristics of lipoproteins defined in the laboratory using ultracentrifugation or electrophoresis.

Treatment of a patient's hyperlipidemia often results in changes in the lipoprotein pattern and laboratory characteristics, so that such a classification has limited value. It is more useful to define the disease or metabolic defect, and as this is becoming increasingly possible, efforts to do this should always be made. Obesity, diabetes, and excess alcohol commonly act on a genetic background to produce hyperlipidaemia. J.P.D. Reckless, (2003)

\section{Prevalence of hyperlipidemia}

The crude population prevalence rates were $41.6 \%$ for hypertension, $42.4 \%$ for hyperlipidemia, $20.2 \%$ for diabetes mellitus, $11.1 \%$ for depression, $23.9 \%$ for hypertension and hyperlipidemia, $12.8 \%$ for hypertension and diabetes mellitus, and $11.5 \%$ for hyperlipidemia and depression. The crude age specific prevalence rates varied across age groups significantly for hypertension (4.5\% to $68.4 \%$ ), hyperlipidemia (3.9\% to $52.3 \%$ ), and diabetes mellitus $(2.8 \%$ to $28.7 \%)$, and significantly less for depression $(5.8 \%$ to $15.0 \%)$. Region adjusted population prevalence rates were $41.2 \%$ for hypertension, $41.8 \%$ for hyperlipidemia, $19.7 \%$ for diabetes mellitus and $11.9 \%$ for depression. Only 87,163 patients with ED (32\%) had no comorbid diagnosis of hypertension, hyperlipidemia, diabetes mellitus or depression.

\section{Justification}

It is a medical condition characterized by an elevation of any or all lipid profile and/or lipoproteins in the blood. This medical condition or problem divided into two subtypes which are: primary hyperlipidemia and secondary hyperlipidemia. Primary hyperlipidemia which is usually taken place as a result of genetic problems i.e., mutation within receptor protein, while secondary hyperlipidemia will arises as a result of other underlining diseases like diabetes. Alteration and/ or abnormality in the metabolism of lipid and lipoproteins is a very common condition that taken place within general population, and it consider as one of the main risk factor in the incidence of cardiovascular disease due to their influence on atherosclerosis.

There are several factors which play significant role in the incidence of this medical problem which are the following: 
family history, chronic diseases (diabetes mellitus, renal failure, nephritic syndrome and hypothyroidism), alcoholism and smoking, obesity and unhealthy diets intake. Hyperlipidemia is caused when your diet contains too much cholesterol and fat (e.g., meat, cheese, cream, eggs, shellfish, etc.), when the body produces too much cholesterol and fat, or both. Fats do not dissolve in water. In order for them to be carried in the blood (which is mostly water) they combine with another substance called a protein to create a lipoprotein.

Too much LDL, or "bad" cholesterol, can build up in the arteries (the blood vessels that carry blood throughout the body) and, over time, cause heart disease or stroke. On the other hand, having too much HDL, or "good" cholesterol, protects the heart by helping to remove the build-up of LDL from the arteries.

Low levels of HDL and high triglycerides can also increase fat build up in the arteries and cause heart disease, especially in people who are obese or have diabetes. Hyperlipidaemia is treated with changes in diet, weight loss and exercise. If necessary, your doctor will also prescribe medication.

The main objectives of this study include to assess the nutritional profile of the hyperlipidaemia Patient. To find out the consumption pattern of selected hyperlipidaemia Patient.

KK et al., (2012) reported that Low Density Lipoproteins (LDL) is thought to be as the 'bad' cholesterol due to higher ratio of cholesterol content to protein and this elevated level may increase the risk of causing heart disease, stroke, etc. Sometime plaque build-up or deposits along the walls of arteries due to which artery become narrow and the flow of blood decreased in the body. Blood flow may obstruct by plaque rupture as it may cause a clotting of blood which may lead to heart attack or myocardial infarction.

Hassan et al., (2013) reported that focus on reducing intake of foods that contain high amount of saturated fat and cholesterol i.e., foods of animal origin. On the other hand this point will encourage intake of food or supplements that include fish oil or olive oil which include a very low concentration of saturated fat. Or focusing on intake of vegetarian foods which are free of cholesterol. These types of food will significant play role in reducing elevated triglyceride levels.

D et al., (2011) reported that hyperlipidaemia acquired because it is caused by another disorder like diabetes, nephritic syndrome, chronic alcoholism and hypothyroidism and with use of drugs like corticosteroids, beta blockers and oral contraceptives. Secondary hyperlipidaemia together with significant hypertriglyceridemia can cause pancreatitis. The main cause of hyperlipidaemia includes changes in lifestyle habits in which risk factor is mainly poor diet in which fat intake form saturated fat and cholesterol exceeds 40 percent of the total calories uptake

Tripathi et al (2008) reported that generally hyperlipidemia does not have any obvious symptoms but they are usually discovered during routine examination or until it reaches the danger stage of a stroke or heart attack. Patients with high blood cholesterol level or patients with the familial forms of the disorder can develop xanthomas which are deposits of cholesterol may form under the skin, especially under the eyes.

At the same time, patients with elevated levels of triglycerides may develop numerous pimple-like lesions at different sites in their body.

\section{Materials and Methods}

The project entitled "To assess the high blood fat nutritional profile, dietary intake and the 
effect of hyperlipidaemia on the health of males and females of Prayagraj district Uttar Pradesh"

The study will be conducted using the following methodology.

Stage 1-Area of the study

Stage 2- Sample selection

Stage 3- Method of enquiry and data collection

Stage 4- Statistical analysis

\section{Selection of city}

The Prayagraj city will be selected purposively for the study.

\section{Sample selection}

The research involved high blood fat aged group, representing the district and effort were made therefore made to locate the subject of varied socio economic background. The respondents selected from the civil hospitals of Prayagraj. Total 15 males and 15 female's age groups of 20-30 years were selected.

\section{Methods of enquiry and data collection}

The survey method was used as the method of enquiry. The selected respondents will personally interviewed and necessary information collected using a pre structured and pretested questionnaire. The questionnaire included aspects which led to the fulfilment of the objectives of this study. 24 hours dietary recall (Swami Nathan) will be done and average nutrient intake per day calculated of each respondents using the nutritive value for Indian foods by Gopalan et.al.

The questionnaire included the following information:
General Profile Survey

Dietary intake (24 hours dietary recall method)

Anthropometric measurement

Clinical sign and symptoms

\section{General profile survey}

Data regarding general profile of the respondents was collected using the first part of the Questionnaire. The section covered aspects including respondent's name, age, type of family, Monthly income, monthly expenditure on food items.

\section{Dietary survey}

Diet surveys constitute an essential part of any complete study of nutritional status of individuals or groups, providing essential information on nutrient intake levels, sources of nutrients, food habits \&amp; attitudes. It will help to following information. A diet survey will be conducted

\section{4 hour dietary recall}

24- Hour dietary recall method is widely used in dietary surveillance. The interviewer asks the respondents questions to obtain information on the types and the amount actually consumed by an individual one or more specific days.

\section{Anthropometric measurement}

Nutritional anthropometry is concern with the measurement of variations of physical dimensions, the gross composition and degree of nutrition. Hence, anthropometric measurements are useful criteria for assessing the nutritional status.

The anthropometric measurement including height and weight are recorded using the process Prescribed by Gibson (1990). 


\section{Height measurement}

Height $(\mathrm{cm})$ of the subject was taken with the help of measuring tape in centimeters by sticking it to the wall. The subject will be made to stand erect, look straight with buttocks, shoulders and head touching the wall, heels together, toes apart and hands hanging loosely by the sides.

\section{Weight measurement}

The weighing scale with maximum capacity of $120 \mathrm{~kg}$ and the minimum division of $0.5 \mathrm{~kg}$ will be used to weigh all the subjects. The respondents will be made to stand erect on the weighing scale with minimum of clothes, without footwear, not learning against and holding anything and the weight was recorded in $\mathrm{kg}$.

Body mass index (BMI) - BMI was calculated as the standard of nutritional status anthropometrically, by using the following formula derived from the weight and height (WHO, 1995).

$$
\mathrm{BMI}=\frac{\text { Weight }(\mathrm{kg}}{\operatorname{Height}\left(\mathrm{m}^{2}\right)}
$$

\section{Clinical signs and symptoms}

The nails, lips, tongs, gums, neck and general appearance of each subject were examined, In order to find out hyperlipidemia, the clinical symptoms of hyperlipidemia in males and females include extreme fatigue, chest pain, heart attack, cramping and calves in walking, trouble speaking, weakness, drooping on one side of the face generally indicate hyperlipidemia.

\section{Statistical analysis}

The collected data will be analysed with the help of t-test, anova and other appropriate statistical technique.

\section{Results and Discussion}

The data collected and tabulated under the study are presented.

\section{General information}

Family type: The majority of respondents, 53 percent belonged to nuclear family and 46 percent respondent belonged to joint family.

Occupation of the family: According to the table most of the respondent family head were in business 30 percent and percent were government and private service and about 50 percent belonged to other occupation (agriculture etc.).

Total family income: showed that 26.6 percent monthly income belonged to below 5000 and 26.6 percent belong to 10,000 $20,000,36$ percent monthly income belong to 21000-25000 rupees and 6.6 percent belong to more than 25000 rupees per month.

Education of the Patient: the majority of the respond belongs to the Uneducated that is 26.6 percent also $30 \%$ percent are primary pass. Followed by graduation belongs to 23.3 per and post-graduation belongs to $20 \%$ percent.

\section{Anthropometric measurements}

Table-2 shows that 13.3 percent of patients were normal BMI, 6.6 percent patients were underweight and obese grade 1 is 20 percent, and grade II were 40 percent patients and obese grade III were 20 percent. MISHRA et al., (2011) reported that hyperlipidaemia relates to increased oxidative stress causing significant production of oxygen free radicals, which may lead to oxidative modifications in low-density lipoproteins, which present a significant function in the initiation and progression of atherosclerosis and associated cardiovascular diseases 


\section{Diet and Nutrient intake}

Table 3- study shows that majority number of respondents 40 percent were vegetarian, 36.6 percent were non-vegetarian and 23.3 percent were eggitarian.

Table 4- shows six the average nutrients intake of all nutrients with reference to energy, protein, fat, calcium, iron, and retinol compared to the RDA given by the ICMR (2010). According to RDA energy intake 1900 and 84.81 percent is consumed by the females patients which shows that they intake energy in good amount, similarly protein intake percent is 63.63 which means that protein intake in the females patients diet is less, the fat intake is more than in the diet of the female patients the fat percentage is 57.14, calcium intake is also very less it is only 58.33 percent, the iron intake is less in the females patients diet is the percentage is 85.71 similarly retinol is 66.66 percent is very less respectively.
Table 5- shows six the average nutrients intake of all nutrients with reference to energy, protein, fat, calcium, iron, and retinol compared to the RDA given by the ICMR (2010). According to RDA energy intake 2320 and 89.230 percent is consumed by the males patients which shows that they intake energy in good amount, similarly protein intake percent is 66.6 which means that protein intake in the males patients diet is less, the fat intake is more than in the diet of the male patients the fat percentage is 60 , calcium intake is also less it is only 41.66 percent, the iron intake is less in the males patients diet is the percentage is 85.71 similarly retinol is 66.6 percent respectively. TJ et al.,(2013) reported that Cholesterol and several other fats together deposit inside the arteries making them narrower by which blood cannot pass easily through it and the pressure may be elevated causing high blood pressure.

Table.1 Distribution of the respondent according to the general information

\begin{tabular}{|c|c|c|c|}
\hline Particulars & Distribution & Frequency & Percentage \\
\hline Family type & Joint & 14 & 46 \\
\cline { 2 - 4 } & Nuclear & 16 & 53 \\
\hline \multirow{3}{*}{ Occupation } & Service & 6 & 20 \\
\cline { 2 - 4 } & Business & 9 & 30 \\
\cline { 2 - 4 } & Any other & 15 & 50 \\
\hline \multirow{3}{*}{$\begin{array}{c}\text { Total family } \\
\text { income }\end{array}$} & Below 5000 & 8 & 26.6 \\
\cline { 2 - 4 } & $5000-10000$ & 9 & 30 \\
\cline { 2 - 4 } & $10000-20000$ & 11 & 36 \\
\cline { 2 - 4 } & $21000-25000$ & 2 & 6.6 \\
\hline \multirow{3}{*}{$\begin{array}{c}\text { Education of the } \\
\text { Patient }\end{array}$} & Uneducated & 8 & 26.6 \\
\cline { 2 - 4 } & Primary & 9 & 23.3 \\
\cline { 2 - 4 } & High school & 7 & 20 \\
\cline { 2 - 4 } & Intermediate & 6 & \\
\hline
\end{tabular}


Table.2 Distribution of hyperglycemic patients according to BMI

\begin{tabular}{|c|c|c|}
\hline BMI Range & Frequency & Percentage \\
\hline 18.5 (underweight) & 2 & 6.6 \\
\hline $18.5-24.9$ (normal ) & 4 & 13.3 \\
\hline $25-29.9$ (obese grade I) & 6 & 20 \\
\hline $30-40$ (obese grade II) & 12 & 40 \\
\hline 40 (obese grade III) & 6 & 20 \\
\hline Total & 30 & 100 \\
\hline
\end{tabular}

Table.3 Distribution of hyperglycemic patients according to the food habits

\begin{tabular}{|c|c|c|}
\hline Food habits & Frequency & Percentage \\
\hline Vegetarian & 12 & 40 \\
\hline Non-Vegetarian & 11 & 36.6 \\
\hline Eggitarian & 7 & 23.3 \\
\hline Total & 30 & 100 \\
\hline
\end{tabular}

Table.4 Average daily nutrients intake of hyperlipidemia females

\begin{tabular}{|c|c|c|c|c|}
\hline RDA & $\begin{array}{c}\text { Reference } \\
\text { value of } \\
\text { females }\end{array}$ & $\begin{array}{c}\text { Average intake } \\
\text { of nutrients of } \\
\text { females }\end{array}$ & $\begin{array}{c}\text { Difference } \\
\text { between ranges } \\
\text { of females }\end{array}$ & $\begin{array}{c}\text { Percentage of } \\
\text { females }\end{array}$ \\
\hline Energy $(\mathrm{kcal})$ & 1900 & 2240 & +340 & 84.82 \\
\hline Protein $(\mathrm{g})$ & 55 & 35.5 & -20 & 63.63 \\
\hline Fat $(\mathrm{g})$ & 20 & 35 & +15 & 57.14 \\
\hline Calcium $(\mathrm{mg})$ & 600 & 350 & -250 & 58.33 \\
\hline Iron $(\mathrm{mg})$ & 21 & 18 & -3 & 85.71 \\
\hline Retinol $(\mu \mathrm{g})$ & 600 & 400 & -200 & 66.6 \\
\hline
\end{tabular}

Source- ICMR, (2010)

Table.5 Average daily nutrients intake of hyperlipidemia males

\begin{tabular}{|c|c|c|c|c|}
\hline RDA & $\begin{array}{c}\text { Reference } \\
\text { value of } \\
\text { Males }\end{array}$ & $\begin{array}{c}\text { Average intake } \\
\text { of nutrients of } \\
\text { Males }\end{array}$ & $\begin{array}{c}\text { Difference } \\
\text { between ranges } \\
\text { of Males }\end{array}$ & $\begin{array}{c}\text { Percentage of } \\
\text { Males }\end{array}$ \\
\hline Energy $(\mathrm{kcal})$ & 2320 & 2600 & +280 & 89.230 \\
\hline Protein $(\mathrm{g})$ & 60 & 40 & -20 & 66.6 \\
\hline Fat $(\mathrm{g})$ & 25 & 40 & +15 & 60 \\
\hline Calcium $(\mathrm{mg})$ & 600 & 250 & -350 & 41.66 \\
\hline Iron $(\mathrm{mg})$ & 17 & 14 & -3 & 85.71 \\
\hline Retinol $(\mu \mathrm{g})$ & 600 & 400 & -200 & 66.6 \\
\hline
\end{tabular}

Source- ICMR, (2010) 
Table.6 Distribution of hyperlipidemia patients according to the food consumption frequency

\begin{tabular}{|c|c|c|c|c|c|c|}
\hline \multirow{2}{*}{ Food group } & \multicolumn{2}{|c|}{ Daily } & \multicolumn{2}{c|}{ Occasionally } & \multicolumn{2}{c|}{ Never } \\
\cline { 2 - 7 } & Frequency & Percentage & Frequency & Percentage & Frequency & Percentage \\
\hline Cereals & 30 & 100 & - & - & - & - \\
\hline Pulses & 20 & 66.66 & 6 & 20 & - & - \\
\hline $\begin{array}{c}\text { Milk \& Milk } \\
\text { products }\end{array}$ & 10 & 33.33 & 10 & 33.33 & 6 & 20 \\
\hline GLVs & 10 & 33.33 & 8 & 26.66 & 12 & 40 \\
\hline $\begin{array}{c}\text { Roots \& } \\
\text { tubers }\end{array}$ & 25 & 83.33 & 5 & 16.66 & - & - \\
\hline Fruits & 5 & 16.66 & 8 & 26.66 & 14 & 46.66 \\
\hline $\begin{array}{c}\text { Meat \& } \\
\text { Poultry }\end{array}$ & 10 & 33.33 & 9 & 30 & 15 & 50 \\
\hline Fats \& Oils & 30 & 100 & - & - & - & - \\
\hline Sugars & 30 & 100 & - & - & - & - \\
\hline
\end{tabular}

Table.7 Distribution of male and female hyperlipidemia patients according to their clinical sign and symptoms

\begin{tabular}{|c|c|c|}
\hline Signs and Symptoms & Frequency & Percentage \\
\hline \multicolumn{3}{|l|}{ Obesity } \\
\hline Absent & 22 & 73.33 \\
\hline & 8 & 26.66 \\
\hline \multicolumn{3}{|l|}{ Chest pain (angina) } \\
\hline Absent & 18 & 60 \\
\hline Present & 12 & 40 \\
\hline \multicolumn{3}{|l|}{ disease } \\
\hline \multirow{3}{*}{$\begin{array}{l}\text { Diabetes } \\
\text { Coronary heart disease } \\
\text { atherosclerosis }\end{array}$} & 14 & 46.66 \\
\hline & 9 & 30 \\
\hline & 7 & 23.33 \\
\hline \multirow{4}{*}{$\begin{array}{l}\text { Eye } \\
\text { Circle fatigue } \\
\text { Pale conjunctiva } \\
\text { Eyelid xanthoma }\end{array}$} & & \\
\hline & 8 & 26.66 \\
\hline & 9 & 30 \\
\hline & 13 & 43.33 \\
\hline \multicolumn{3}{|l|}{ Tongue } \\
\hline Furred & 18 & 60 \\
\hline Light brown & 12 & 40 \\
\hline \multirow{3}{*}{$\begin{array}{l}\text { Skin } \\
\text { Yellowish orange deposits } \\
\text { Eruptive xanthomatosis }\end{array}$} & & \\
\hline & 12 & 40 \\
\hline & 18 & 60 \\
\hline
\end{tabular}

Table 6- shows that the food consumed daily by all respondents included cereals, pulses, milk and milk products, green leafy vegetables, roots and tubers, fruits, meat and 
poultry, fats and oils and sugar. Regarding the consumption of cereals, it was found that all respondent consumed cereals daily. Pulses were consumed daily by 66.6 percent respondents because they know it contain many nutrients. Milk and milk products were consumed daily by 33.33 percent respondents consumed, 40 percent respondent consumed occasionally and 20 percent respondent consumed never.

Regarding green leafy vegetable they were consumed daily 33.33 percent, 26.66 percent respondents consumed them occasionally and 40 percent never consumed.

Meat and poultry were consumed by 33.33 percent respondents daily, 30 percent occasionally and 33.3 percent never consumed. Fats and oils and sugar were consumed almost daily by the respondents. KY et al., (2006) reported that numerous studies have clearly established that hypercholesterolemia leads to an inflammatory response within the microvasculature, reflected by endothelial cell activation, leukocyte recruitment, rolling and adherence, as well as platelet activation.

Table-7 shows that obesity was 73.33 percent and chest pain was present in 60 percent. Disease like diabetes 46.66 percent coronary heart disease 30 percent and atherosclerosis were present in 23.33 percent. Dark circle of fatigue were present in 26.66 percent and pale conjunctiva were present in 30 percent and eyelid xanthoma 43.33 percent respectively.

Furred tongue were seen 60 percent respectively and eruptive xanthomatosis were 60 percent respectively. Yellowish orange deposits were 40 percent respectively and eruptive xanthomatosis were observed in 60 percent.

In conclusion this study provides, clinical symptoms, nutritional profile, and
Consumption pattern among the hyperlipidemia female and male patients of middle age group. Hyperlipidemia is caused when your diet contains too much cholesterol and fat (e.g., meat, cheese, cream, eggs, shellfish, etc.), when the body produces too much cholesterol and fat, or both. Fats do not dissolve in water. In order for them to be carried in the blood (which is mostly water) they combine with another substance called a protein to create a lipoprotein. Too much LDL, or "bad" cholesterol, can build up in the arteries (the blood vessels that carry blood throughout the body) and, over time, cause heart disease or stroke. On the other hand, having too much HDL, or "good" cholesterol, protects the heart by helping to remove the build-up of LDL from the arteries. Low levels of HDL and high triglycerides can also increase fat build up in the arteries and cause heart disease, especially in people who are obese or have diabetes. Hyperlipidaemia is treated with changes in diet, weight loss and exercise. If necessary, your doctor will also prescribe medication.

\section{References}

The Scandinavian Simvastatin Survival Study (4S) (1994) Randomised trial of cholesterol lowering in 4444 patients with coronary heart disease. Lancet 19: 1383-1389.

De Lorgeril M (2014) Cholesterol and statins. Sham science and bad medicine. Thierry Souccar Publishing, Vergèze, France.

Miller CL, Assimes TL, Montgomery SB, Quertermous T (2014) Dissecting the causal genetic mechanisms of coronary heart disease. Curr Atheroscler Rep 16: 1-406.

Awad AB, Fink CS (2000) Phytosterols as anticancer dietary components: evidence and mechanism of action. $J$ Nutr 130: 21272130. 
Berge KE, Schultz J, Kwiterovich P, Shan B, Barnes R, et al. (2000) Accumulation of dietary cholesterol in sitosterolemia caused by mutations in adjacent $\mathrm{ABC}$ transporters. Science 290: 1771-1775.

NIH (2011) NIH stops clinical trial on combination cholesterol treatment.

Abourbih S, Filion KB, Joseph L, Genest J, Eisenberg MJ, et al. (2009) Effect of fibrates on lipid profiles and cardiovascular outcomes: A systematic review. Am J Med 122: 962. e1-8.

Ginghina, C., Bejan, I.,Ceck, C. D.(2011) Modern risk stratification in coronary heart disease.J. Med. Life.; 4(4): 377-86. Jorgensen, T., Capewell, S., Prescott, E., Allender, S., Sans, S.,Zdrojewski, T.(2013) Population-level changes to promote cardiovascular health. Eur. J. Prev. Cardiol., ; 20(3):409-21.

Ference BA, Yoo W, Alesh I, Mahajan N, Mirowska KK, et al. (2012) Effect of long-term exposure to lower lowdensity lipoprotein cholesterol beginning early in life on the risk of coronary heart disease: A Mendelian randomization analysis. $J$ Am Coll Cardiol, 60: 2631-2639.

Bassam Abdul Rasool Hassan(2013) Clinical Pharmacy Discipline, School of Pharmaceutical Sciences, University of
Sains Malaysia, 11800, Minden, Penang, MalaysiaHassan, J Chromat Separation Techniq , 4:2

Joseph, D. (2011) Pharmacotherapy, A pathophysiological approach, $8^{\text {th }}$ edn, The McGraw Hill companies, Inc; pp370.

Mishra, P. R., Panda, P. K., Apanna, K.C., Panigrahi, S.(2011) Evaluation of acute hypolipidemic activity of different plant extracts in Triton WR-1339 induced hyperlipidemia in albino rats. Pharmacologyonline.;3: 925-934.

Tripathi,K.D. (2008) Essentials of medical pharmacology, $66^{\text {th }}$ edn,Inda: $J P$ brothers medical publishers, pp613614.

Anderson TJ, Gregoire J, Hegel RS, Stone JA, Ur E, et al. (2013) Update of the Canadian cardiovascular soceity guidelines for the diganosis and treatment of dyslipidemia for the prevention of cardiovascular disease in the adult. Can J Cardiol 29: 151-167.

Stokes KY, Calahan L, Russell JM, Gurwara S, Granger DN (2006): Role of platelets in hypercholesterolemia-induced leukocyte recruitment and arteriolar dysfunction. Microcirculation, 13: 377388. 10.1080/10739680600745877.

\section{How to cite this article:}

Kushwaha Pratibha, Gupta Alka and Paul Virginia. 2021. To Assess the High Blood Fat Nutritional Profile, Dietary Intake and the Effect of Hyperlipidaemia on the Health of Males and Females (Middle age group) of Prayagraj District Uttar Pradesh. Int.J.Curr.Microbiol.App.Sci. 10(01): 3223-3232. doi: https://doi.org/10.20546/ijcmas.2021.1001.375 